San Jose State University

SJSU ScholarWorks

Master's Theses

Master's Theses and Graduate Research

Summer 2015

\title{
The Moderating Effect of Supervisory Social Support on the Relationship between Second Generation Latinos' and Asians' Assimilation Level and Work-Family Conflict
}

Yazmin Perez-Lopez

San Jose State University

Follow this and additional works at: https://scholarworks.sjsu.edu/etd_theses

\section{Recommended Citation}

Perez-Lopez, Yazmin, "The Moderating Effect of Supervisory Social Support on the Relationship between Second Generation Latinos' and Asians' Assimilation Level and Work-Family Conflict" (2015). Master's Theses. 4607.

DOI: https://doi.org/10.31979/etd.q8w9-sqd8

https://scholarworks.sjsu.edu/etd_theses/4607

This Thesis is brought to you for free and open access by the Master's Theses and Graduate Research at SJSU ScholarWorks. It has been accepted for inclusion in Master's Theses by an authorized administrator of SJSU ScholarWorks. For more information, please contact scholarworks@sjsu.edu. 
THE MODERATING EFFECT OF SUPERVISORY SOCIAL SUPPORT ON THE RELATIONSHIP BETWEEN SECOND GENERATION LATINOS' AND ASIANS' ASSIMILATION LEVEL AND WORK-FAMILY CONFLICT

\author{
A Thesis \\ Presented to \\ The Faculty of the Department of Psychology \\ San Jose State University \\ In Partial Fulfillment \\ of the Requirement for the Degree \\ Master of Science
}

by

Yazmin Perez-Lopez

August 2015 
(C) 2015

Yazmin Perez-Lopez

ALL RIGHTS RESERVED 
The Designated Thesis Committee Approves the Thesis Titled

THE MODERATING EFFECT OF SUPERVISORY SOCIAL SUPPORT ON THE RELATIONSHIP BETWEEN SECOND GENERATION LATINOS' AND ASIANS' ASSIMILATION LEVEL AND WORK-FAMILY CONFLICT

by

Yazmin Perez-Lopez

August 2015

Dr. Megumi Hosoda

Department of Psychology

Dr. Howard Tokunaga

Department of Psychology

Felicia Mena

El Capitan Middle School 


\section{ABSTRACT \\ THE MODERATING EFFECT OF SUPERVISORY SOCIAL SUPPORT ON THE RELATIONSHIP BETWEEN SECOND GENERATION LATINOS' AND ASIANS' ASSIMILATION LEVEL AND WORK-FAMILY CONFLICT \\ By Yazmin Perez-Lopez}

The majority of the empirical work regarding work-family conflict (WFC) has been focused on the experiences of White, middle class, Anglo-Americans. The labor force, however, is experiencing major demographic changes as increasing numbers of U.S.-born Latinos and Asians become employees. Although second generation Latinos and Asians play a major role in the U.S. economy and workplace, their experiences as employees have seldom been examined. Because they are exposed to collectivistic and individualistic values simultaneously, their assimilation levels, or identification with the U.S. culture, could be a unique predictor of a type of WFC: work-interference with family (WIF) or family interference with work (FIW). Using 103 second generation Latino and Asian employees, the present study was aimed to understand the influence of cultural variables on WFC by examining the relationship between their assimilation levels and type of WFC. It was hypothesized that the more assimilated they were, the more WIF and the less FIW they would experience. In addition, perceived supervisor support was introduced as a moderator of the relationship between assimilation levels and type of WFC. The findings of this study revealed that contrary to the hypothesis, assimilation levels were not related to WIF or FIW, nor did perceived supervisor support moderate their relationship. However, the study did provide further evidence that perceived supervisor support could reduce WIF. Given these findings, organizations should look to revamp their work-family balance initiatives and provide the necessary training to their front-line supervisors to instill a sense of supervisory support among employees. 


\section{ACKNOWLEDGEMENTS}

I would like to begin by expressing my most sincere gratitude to Dr. Megumi Hosoda for all of her patience and encouragement and for pushing me to be a better writer every step of the way. Without her, this achievement would have been impossible. Thank you, Dr. Megumi Hosoda. I would also like to thank Dr. Howard Tokunaga for providing me with valuable insight and support throughout the entire process. To all of my dear friends, who always reminded me that I CAN, and I WILL, especially Odilva Moreno....my changa, my person, and Casey Campbell for all of his wisdom. Also, I would like to thank my family for being who they are, especially my parents who have always allowed me to carve my own path in life even if it meant living hundreds of miles away across the country, or in foreign lands. Thank you for instilling in me the value of hard work and dedication. Gracias por siempre ayurdarme con lo que sea, y por criarme con mi cultura Mexicana! This thesis was inspired by you and is dedicated to YOU. Last but not least, to the love of my life, and my rock- Richard Roth. I could not have asked for a better partner in life, and I will forever be grateful to you for carrying me through this one. I love you. To my nieces and nephew who inspire me every day...I love you! 


\section{TABLE OF CONTENTS}

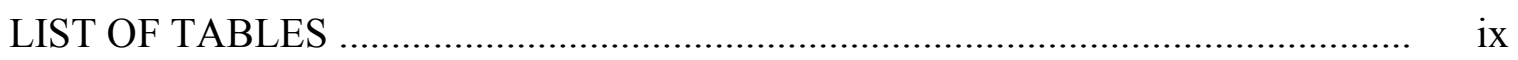

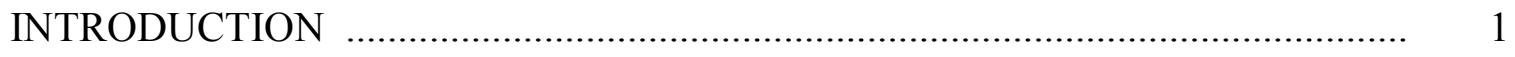

Work-Family Conflict and Assimilation Level …………………………..... 4

Research on Type of WFC Among Second Generation Latinos and Asians . 9

Moderating Effect of Perceived Supervisor Support …………………….... 12

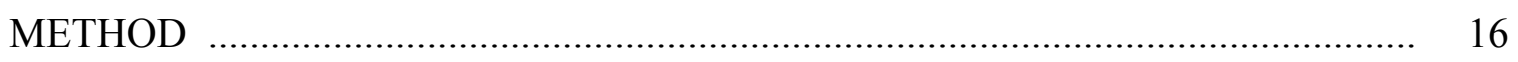

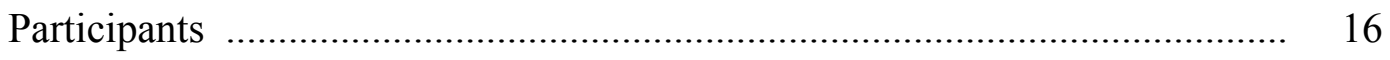

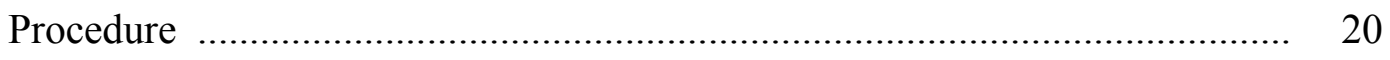

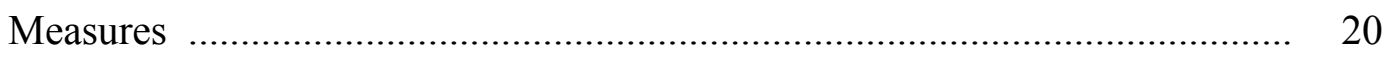

Assimilation level ..................................................................... $\quad 20$

Type of work-family conflict _....................................................... 21

Perceived supervisor support ………………………………...... 22

Demographic information ........................................................... 22

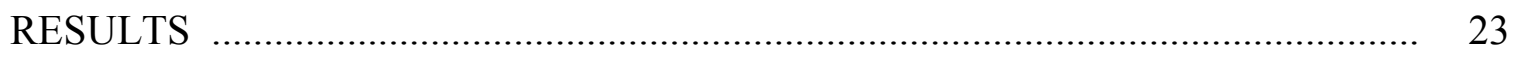

Descriptive Statistics ......................................................................... 23

Pearson Correlations .............................................................................. 23

Test of Hypothesis and a Research Question ............................................... 24

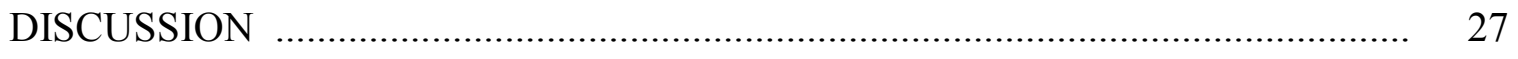

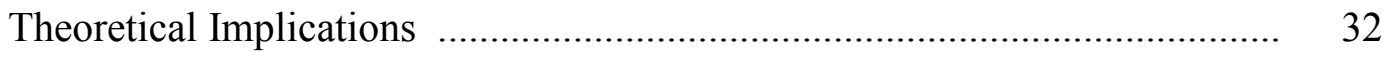

Practical Implications 
Conclusion 


\section{LIST OF TABLES}

Table 1. Descriptive Information ..................................................................... 18

Table 2. Means, Standard Deviations, Pearson Correlations, and Alphas ............... 23

Table 3. Hierarchical Regression Analysis Summary for Variables Predicting Work Interfering with Family ............................................................................ 25

Table 4. Hierarchical Regression Analysis Summary for Variables

Predicting Family Interfering with Work 


\section{Introduction}

Latinos and Asians have long been the nation's fastest growing ethnic groups. According to the U.S. Census Bureau (2012), the Latino population grew by over 1.1 million between 2011 and 2012, reaching over 53 million. Comparatively, the Asian population increased by 530,000 in 2011, reaching 18.9 million in 2012. Although currently the Latino and Asian populations are mostly composed of first generation immigrants, the U.S.-born population, or the second generation, is rapidly increasing due to a decreasing inflow of immigrants and high fertility rates (Fry \& Lowell, 2002). In fact, $20 \%$ of adult Latinos and $27 \%$ of adult Asians represented the second generation in 2013 (Pew Research Center, 2013).

The labor force is also undergoing a major generational shift because increasing numbers of today's young U.S.-born Latino and Asian Americans are entering the workforce (Fry \& Lowell, 2002). It is projected that by the year 2050, the workforce will be composed of $24 \%$ second-generation Latinos and $11 \%$ second-generation Asians (Toossi, 2002). Given the statistics that second generation Latinos and Asians occupy a large segment of the American population and are increasing in numbers as workers, they will continue to play an important role in the U.S. economy and workplace. However, their experiences as employees have seldom been examined (Pew Research Center, 2013). Instead, the few studies that have examined the experiences of Latinos and Asians in the workplace solely were focused on immigrants, not on second generation individuals. 
It is important to study the experiences of second generation Latinos and Asians because unlike the first generation, they are likely to be exposed to two different cultures simultaneously, their ethnic culture and the dominant culture of the U.S. Whereas the Latino and Asian ethnic cultures are classified as collectivist, the dominant culture of the U.S. and its workplace are defined as individualistic, and differ in values, customs, and traditions (Hofstede, 1983). Therefore, second generation Latinos and Asians might experience conflicting pressures and responsibilities, deeply embedded in the values of collectivism and/or individualism at home and/or in the workplace. Consequently, they may experience conflict between their work and family lives. However, second generation Latinos and Asians may differ in their experiences of conflict due to their identification with the U.S. culture or, in other words, their assimilation levels. Assimilation occurs when "individuals shed their ethnic culture, and become absorbed into the dominant society" (Sam \& Berry, 2010, p.476).

According to work/family border theory, a firm boundary between the workplace and family life exists, implying that going from work to home and vice versa is similar to crossing the border between two countries (Campbell-Clark, 2000). The theory's main argument is that work and family are different domains that influence each other, yet they differ in purpose and in culture. Specifically, work and home can be compared to two different countries that differ in communication, acceptable behavior, and in the means to accomplish tasks.

Work/family border theory proposes that for some individuals, the transition from work to family is minor, for example, between two neighboring countries that share the 
same language, currency, and customs (Campbell-Clark, 2000). For others, the difference is much greater, thus requiring a more drastic transition. "People are bordercrossers who make daily transitions between these two settings, often tailoring their focus, their goals, and their interpersonal style to fit the unique demands of each" (Campbell-Clark, p.751). Based on the theory, it is assumed that second generation Latino and Asian employees might struggle with larger differences in their family and work domains than the general population of Anglo-Americans due to their exposure to two contrasting cultures: collectivism at home and individualism at work. The theory not only emphasizes the importance of studying this population, but also highlights the need to understand how their assimilation levels might shape their experiences of work-family conflict.

Work-family conflict (WFC) is defined as "inter role conflict in which the role demands from work are incompatible with the role demands from family" (Greenhaus \& Beutell, 1985, p.77). WFC is bidirectional such that work can interfere with family (WIF) or family can interfere with work (FIW). One example of WIF is when an individual must work long hours that delay the fulfillment of household responsibilities (Fu \& Shaffer, 2001), whereas an example of FIW is when an individual is unable to attend work due to the illness of an elderly parent (Gutek et al., 1991).

To the author's best knowledge, no research has examined the relationship between second generation Latino and Asian employees' assimilation levels and the specific type of work-family conflict they might experience. Because the majority of the empirical work on WFC has been collected from Anglo-American, middle class, 
professionals, who reflect the values, family structure, and work history of the dominant group in society, this study adds to the literature by examining experiences of second generation Latinos and Asians, a minority group with exposure to collectivist and individualistic values (Barnett \& Hyde, 2001). An understanding of assimilation levels and how they impact the attitudes and behaviors of this population may help organizations develop more effective work-family balance initiatives.

Furthermore, perceived supervisor support has been shown to reduce WFC (Benson, 2002; Clark, 2001), yet no research has examined perceived supervisor support as a moderator in the WFC literature. In this study, perceived supervisor support was explored as a potential mitigating factor of the relationship between assimilation level and type of WFC among second generation Latinos and Asians.

Sections below entail a review of the literature that serves as the theoretical basis for this study and present the hypothesis and research question that were tested. In sum, this study assessed the relationship between second generation Latino and Asian employees' assimilation levels and type of WFC experienced: family interference with work or work interference with family, and the moderating effect of perceived supervisor support on these relationships.

\section{Work-Family Conflict and Assimilation Level}

Greenhaus, Collins, and Shaw (2003) have asserted that participation in the work (family) role is made more difficult by participation in the family (work) role because the demands of work and home are often incompatible, making it difficult for individuals to fulfill the responsibilities of each domain. This concept is conceptualized as work family 
conflict, defined as "inter role conflict in which the role demands from work are incompatible with the role demands from family" (Greenhaus \& Beutell, 1985, p.77).

WFC has been found to have ramifications for the physical and psychological well-being of individuals and their families, as well as for the bottom line of organizations (Gelder, 2012). For example, individuals who experience WFC have been found to experience increased health risks, psychological distress, and negative moods (Frone, Russel \& Cooper, 2000; Judge, Ilies, \& Scott, 2006). WFC has also been found to lead to poor marital adjustment, lower life and marital satisfaction, as well as poor performance as a marital partner and parent (e.g. Greenhaus \& Beutell, 1985; Near et al., 1978; Suchet \& Barling, 1986). The inability to deal with the demands of both work and family has also presented itself in the workplace through increased absenteeism, higher turnover rates, and lower organizational commitment (Fernandez, 1986; Schultz \& Henderson, 1985). Moreover, higher levels of WFC have also been found to reduce productivity, job satisfaction, and employee morale (Higgins, Duxbury, \& Irving, 1992).

Given these negative outcomes associated with WFC, researchers have identified antecedents of WFC, such as work and family characteristics leading to a specific type of WFC experienced; work interfering with family (WIF) or family interfering with work (FIW) (Frone, 2000). Work characteristics refer primarily to pressures arising from excessive workloads and workplace time pressures such as rush jobs and deadlines. For example, it has been found that WIF is greater among individuals who report numerous work demands and demonstrate a greater time commitment to work (Fenwick \& Tausig, 2001; Parasuraman \& Simmers, 2001; Yang, Chen, Choi, \& Zou, 2000). In contrast, 
family characteristics refer primarily to time pressures associated with tasks like housekeeping and child care, as well as the number of dependents, family size, and family structure (e.g., Frone et al., 1992; Near, Rice, \& Hunt, 1980). For example, FIW has been reported to be greater among individuals with children and elderly parents in need of special care (Behson, 2002; Carlson \& Perrewe, 1999; Grzywacz, \& Marks, 2000), those who experience high levels of stress at home due to conflict with family members (Carlson \& Perrewe, 1999; Fox \& Dwyer, 1999; Grzywacz \& Marks, 2000), as well as those who have time-consuming family obligations (Parasuraman \& Simmers, 2001).

Despite the vast research on the work-family interface, the understanding of this topic remains limited due to its exclusive focus on middle class, Anglo-American professionals who may differ in cultural values and economic circumstances from minority employees (Spector et al., 2004). Anglo-American professionals may only be exposed to the individualistic and dominant culture of the U.S., whereas second generation Latinos and Asians are exposed to both their individualistic dominant culture and their collectivistic ethnic culture. Therefore, the experiences of WFC for second generation Latinos and Asians might differ depending on their level of assimilation into the dominant U.S. culture.

Specifically, a more prevalent type of WFC (WIF or WIF) among second generation Latinos and Asians may exist, depending on their identification with the dominant culture. For example, individuals who identify more with a culture that has high expectations regarding family involvement, interconnectedness and adherence to 
gender roles (i.e., non-assimilated Latinos and Asians) may experience more motivation to participate in the family domain (Rodriguez, 2009). As a result, adherence to collectivistic cultural expectations of time commitment to family may lead to more FIW by increasing time and role demands to their family, because the individuals might have less time and resources for the work role. In contrast, individuals who identify mainly with a culture that values a strong focus on career goals (i.e., Anglo Americans or highly assimilated Latinos and Asians) may dedicate more time to fulfill work responsibilities, as is often rewarded in individualistic countries such as the U.S. Consequently, more identification with an individualistic culture may lead individuals to experience more WIF by increasing time and role demands to work, because they dedicate less time and resources for their family roles (Rodriguez, 2009).

As mentioned earlier, assimilated second generation Latinos and Asians who identify more with their dominant culture than with their ethnic culture might experience more WIF and less FIW. Consequently, one unique predictor of the type of WFC experienced among second generation Latinos and Asians might be their assimilation levels. Assimilation occurs when "individuals prefer to shed their ethnic culture, and become absorbed into the dominant society" (Sam \& Berry, 2010, p.476). According to Sam \& Berry (2010), "assimilation is the strategy used when individuals do not wish to maintain their cultural identity and seek close interaction with other cultures (or in some cases adopt the cultural values, norms, and traditions of the new society)" (p. 475). This study defined assimilation as the extent to which second generation Latinos and Asians identify themselves with the individualistic dominant culture of the U.S. and workplace. 
Statistical findings with second generation Latinos and Asians provide a glimpse into the assimilation trends of this population, providing the foundation for this study. According to the 2013 results of the Pew Research Center, only $37 \%$ of second generation Latinos and $27 \%$ of Asian Americans identify themselves as simply "American," choosing instead to identify themselves with their ethnic culture, or their family's country of origin. However, compared with the first generation population, they are more likely to speak English, have friends and spouses outside their ethnic group, and define themselves as a "typical American” (Pew Research, 2013). Therefore, it is inferred that although second generation Latino and Asians identify themselves with their ethnic culture, many of them also identify themselves with the dominant U.S. culture, which could mean that some may feel torn between collectivist and individualistic values, but others may not feel such conflict, emphasizing the need to understand the role individual assimilation levels play in work-family conflict.

Assimilation research has shown that in general, second generation Latinos and Asians often struggle in fulfilling the demands of their collectivist family and participating in an individualistic environment at the same time. For example, researchers have found that poor academic performance is often a result of the competing demand to help family and excel in school (Suárez-Orozco \& Suárez-Orozco, 1995). Research has also found that second generation Latino and Asian working women tend to experience difficulties managing the demands of their culturally prescribed gender roles, where women are expected to maintain the household (Gibson \& Bhachu, 1991; McHale et al., 1999). Based on these findings, it may be inferred that second generation Latino 
and Asians might experience a specific type of work-family conflict more than others, however, this may differ based on their assimilation levels. Through an understanding of the type of conflict individuals tend to experience based on their assimilation levels, organizations can better manage work-family conflict in the workplace.

\section{Research on Type of WFC Among Second Generation Latinos and Asians}

Studies that have included second generation Latinos and Asians in their examination of the specific type of WFC experienced are scarce and the results are inconsistent. Some studies indicate that second generation Latinos and Asians tend to report more FIW than WIF. For example, Hill, Yang, Hawkins, and Ferris (2004) found that Chinese-Americans reported more FIW compared to their Anglo-American counterparts, indicating that Chinese Americans claimed that they were more concerned with family issues while they were at work than with work issues while they were with their family members. Moreover, Vuong (2010) found similar findings in a sample of 104 second generation Chinese-Americans such that they experienced greater FIW than WIF. Vuong specifically found that participants felt a stronger obligation to satisfy their family's needs than to meet deadlines at work. The findings were explained through the notion that in many immigrant families, family members rely on the assistance of their U.S.-born offspring because of language barriers and a lack of knowledge about American culture by their immediate family members. Although Vuong did not examine the assimilation levels of these second generation Chinese-Americans, these findings might be due to the lack of their assimilation into the U.S. dominant culture, or perhaps 
even assimilated second generation Americans might experience more FIW than WIF, mainly due to their family members' excessive reliance on them.

Similarly, Grzywacz et al. (2006) conducted a study with 1,213 White, Black, Hispanic, and Asian American nurses in order to better understand the demographic correlates of WIF and FIW. The researchers did not specify whether these Hispanic and Asian nurses belonged to the second generation; however, they found Hispanics and Asians reported less WIF and more FIW than did their White and Black counterparts. Again, their assimilation levels were not measured in this study, yet these differences in the type of WFC might be due to the fact that these Hispanic and Asian nurses were not assimilated and shared similar collectivist values, which led to more FIW, whereas Blacks and Whites shared similar individualistic values, which led to more WIF.

Although the above studies seem to indicate that second generation Latinos and Asians might report more FIW than WIF, it could be based on a lack of assimilation into the dominant culture. Other studies have indicated that assimilated Latinos and Asians share the same values as Anglo-Americans who identify themselves with the individualist dominant culture, and therefore experience similar levels and types of WFC as AngloAmericans. For example, Olson, Huffman, Leiva, and Culbertson (2013), studying 309 Caucasian and Latino employees, found that the level of adherence to the U.S. dominant culture, or assimilation, was related to WFC. They specifically found that individualism was directly related to WIF, indicating that the more employees in either group adhered to individualistic values, the more they reported work interfering with their home lives (WIF), but not necessarily their home lives interfering with their work (FIW). 
Furthermore, Olsen et al. found that it was cultural values (i.e., individualism) and not ethnicity that contributed to differences in levels of WIF among Latino and Caucasian employees.

In the same vein, Gelder (2012) examined the influence of individualistic cultural orientations on WIF. It was predicted that individuals who identified themselves as an individualist would endorse higher levels of WIF and that those who identified themselves as a collectivist would endorse lower levels of WIF. Using a sample of 203 professional Latinas, the researcher hypothesized that those who scored high in individualism would be more likely to prioritize their individual needs over those of the family. This study found that participants who held more of an orientation reflective of individualism did in fact report higher levels of WIF than those who held more of an orientation reflective of collectivism, and found that collectivism was not related to WIF. Although assimilation level was not directly measured, the results of this study indicate that highly assimilated second generation Latinos and Asians may experience more WIF than non-assimilated individuals.

Ross et al. (2014) compared two individualistic countries (Australia and the United States) with two collectivistic countries (Japan and South Korea) on WFC. They expected collectivists to experience more WFC than individualists, yet they found that individualists experienced more WFC than collectivists. They further analyzed their results by conducting ANCOVAS with hours worked per week as a covariate and individualism and collectivism as a between-subjects factor. Even after finding a significant relationship between hours worked per week and WFC, individualists 
experienced greater WFC than collectivists. The researchers explained these findings by stating that individualists reported not having enough time to spend with their families. Although WIF or FIW were not measured in this study, perhaps the results indicate that individualists allow work to interfere with their family time more than collectivists. Furthermore, although this study was not conducted with second generation Latino and Asian Americans, it does provide insight into the type of WFC they may encounter depending on their assimilation level. In line with the findings of Olson et al. (2013) and Gelder (2012), it is argued that adherence to individualism is related to WIF, but not necessarily to FIW.

As previously mentioned, the studies discussed above did not measure the assimilation level of their participants, but their findings demonstrate how individual variations in cultural values may affect the ways in which individuals experience conflict between work and family domains. Perhaps second generation Latinos and Asians who

are assimilated share similar values with Anglo-Americans and experience more WIF and less FIW. Given these findings, this study tested the following hypothesis:

Hypothesis 1: The more assimilated second generation Latinos and Asians are, the more WIF and the less FIW they will experience.

\section{Moderating Effect of Perceived Supervisor Support}

As mentioned earlier, the present study also sought to examine perceived supervisor support as a potential moderator of the relationship between assimilation level and type of work-family conflict. Perceived supervisor support is defined as the extent to 
which employees feel their supervisors value their contributions and care about their well-being (Eisenberger, Stinglhamber, Vandenberghe, Sucharski, and Rhoades, 2002).

The majority of the research that has examined the effects of social support on work-family conflict has been focused on matching domain relationships, that is, how social support in the work domain is related to WIF and how social support in the family domain is related to FIW. In particular, research has shown that the domain-specific effects of social support are especially strong; for example, support from a partner reduces FIW, whereas support from one's supervisor reduces WIF (Bellavia \& Frone, 2005). Because organizations may be more easily influenced than family members, to implement changes that help reduce WFC (e.g. corporate policies, work life balance initiatives), this study focused on the specific effects of supervisor support on the type of work-family conflict experienced. Furthermore, Lindorff (2000) argues that the perception of support buffers the effects of stressors on strains more than self-reports of actual support, meaning that perceived support is likely responsible for the effects that it has on stress. Hence, this study examined the effects of perceived supervisor support. Various studies have found that supervisor support reduces WFC (Mauno et al. 2005; Behson, 2002; Clark, 2001; Thompson et al., 1999). However, empirical evidence on the moderating effects of supervisor support is less clear. To the author's best knowledge, no studies have examined the moderating effects of perceived supervisory support on the relationship between assimilation level and type of WFC experienced by second generation Latinos and Asians. However, some studies have studied the moderating effects of perceived supervisor support. For example, the work stress- 
burnout relationship has been found to be moderated by supportive supervisory relationships (Etzion, 1984). More specifically, in the presence of supervisor support, less burnout resulted from work stressors. Moreover, Karasek, Triantis, and Chaudhry (1982) examined the ability of social support to buffer stressor-strain relationships and found that a higher level of perceived supervisory support was associated with a weaker relationship between job task characteristics and strain symptoms; specifically, individuals in high stress job situations reported lower psychological strain in the presence of perceived supervisory support.

Although no studies have used perceived supervisor support as a moderator on the relationship between assimilation level and type of WFC, perhaps the relationship between assimilation level and WFC for second generation Latinos and Asians may be weakened in the presence of perceived supervisor support. For those individuals who identify with the dominant culture (assimilated), perceived supervisor support may weaken WFC by displaying supportive behaviors. For example, a supervisor might allow flexible work hours or adjust workloads to provide better work-life balance to their employees and hence they may experience less WIF. Although perceived supervisor support is often associated with the work domain, it may still moderate the relationship between assimilation level and FIW because supervisors often dictate the level of workfamily balance employees receive. For example, a supervisor might offer an employee assistance program, accommodate personal emergencies, and implement an open-door policy to discuss any issues, hence employees may experience less FIW. 
Perceived supervisor support is an important consideration in the overall evaluation of the work-family conflict topic and may help organizations identify whether it can weaken the relationship between assimilated individuals and WIF. Therefore, this study sought to answer the following research question:

Research question: Will perceived supervisor support moderate the relationship between assimilation level and the type of work-family conflict (WIF and FIW) experienced by second generation Latinos and Asians? 


\section{Method}

\section{Participants}

A total of 138 individuals participated in the study. Participants who had a large proportion of incomplete responses were excluded from the study; therefore, the final sample consisted of 103 participants. Criteria to participate in the study were that individuals must have been employed at the time of data collection, must be of Latino or Asian descent, and must be a member of the second generation.

Table 1 summarizes the demographic information of the participants. The sample consisted of $35 \%$ males and $65 \%$ females. The majority of the participants reported that they identified themselves as Latino (64.1\%), followed by $29.1 \%$ of the participants reporting that they identified themselves as Asian, and 6.8\% indicating that they belonged to either the Latino or Asian race along with a different race, or both the Latino and Asian races. The participants' ages ranged from 17 to 58 years old $(M=29.11, S D=6.50)$. Furthermore, most participants $(60 \%)$ were single without children. In terms of living structure, $36.9 \%$ reported living in a household with their immediate family (significant other and/or children) or living in a household with parents and/or siblings (28\%). In addition, $54 \%$ reported that no family members financially depended on them.

In terms of employment, participants worked across a variety of industries, with the majority working in health care or social assistance $(21.4 \%)$, professional, scientific or technical services $(17.5 \%)$, and educational services $(12.6 \%)$. Although the length with a current employer ranged from .08 to 30 years, on average, participants reported that they had been with their current employer for four years $(M=4.03, S D=4.29)$. 
Furthermore, the length under a current supervisor ranged from .08 to 15 years but, on average, participants reported working under their current supervisor for less than three years $(M=2.58, S D=2.95)$. Only a small number of participants $(15.5 \%)$ reported that they held a managerial position. 
Table 1

Descriptive Information $(n=103)$

\begin{tabular}{lcc}
\hline Demographics & $n$ & $\%$ \\
\hline Age & $\mathrm{M}=29.11$ & $\mathrm{SD}=6.50$
\end{tabular}

Gender

Male

Female

$36 \quad 35.0 \%$

$67 \quad 65.0 \%$

Race

Hispanic

Asian/Pacific Islander

Other

$66 \quad 64.1 \%$

$30 \quad 29.1 \%$

$7 \quad 6.8 \%$

Marital and Parental Status

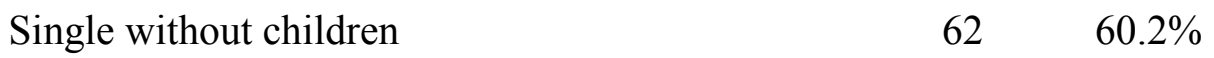

Single with children $\quad 4 \quad 3.9 \%$

Married without children $\quad 12 \quad 11.7 \%$

Married with children $\quad 19 \quad 18.4 \%$

Life partner without children $\quad 4 \quad 3.9 \%$

$\begin{array}{ll}\text { Life partner with children } & 2\end{array}$

Household Structure

Living in a household by oneself.

$13 \quad 12.6 \%$

Living in a household with one's immediate

family (significant other and/or children)

$38 \quad 36.9 \%$

Living in a household with one's parents

and/or siblings

$29 \quad 28.2 \%$

Living in a household with one's extended family members only.

$1 \quad 1.0 \%$

Living in a household with sub-famillies

composed of relatives including immediate

family members; for example parents, in-

laws, grandparents, cousins, etc.

Living in a household with unrelated

individuals.

$\begin{array}{rr}6 & 5.8 \% \\ 16 & 15.5 \%\end{array}$

Industry

Forestry, fishing, hunting or agriculture

$1 \quad 1.0 \%$

Construction

$2 \quad 1.9 \%$

Manufacturing

$3 \quad 2.9 \%$

(continued) 
Table 1

Descriptive Information $(n=103)$

\begin{tabular}{lrr} 
Demographics & \multicolumn{1}{c}{$\%$} \\
\hline Wholesale trade & 2 & $1.9 \%$ \\
Retail trade & 7 & $6.8 \%$ \\
Transportation or warehousing & 3 & $2.9 \%$ \\
Information & 5 & $4.9 \%$ \\
Finance or insurance & 2 & $1.9 \%$ \\
Real estate or rental and leasing & 2 & $1.9 \%$ \\
Professional, scientific, technical services & 18 & $17.5 \%$ \\
Management of companies or enterprises & 5 & $4.9 \%$ \\
Admin, support, waste management or & & \\
remediation services & 2 & $1.9 \%$ \\
Educational services & 13 & $12.6 \%$ \\
Health care or social assistance & 22 & $21.4 \%$ \\
Arts, entertainment or recreation & 3 & $2.9 \%$ \\
Accommodation or food services & 4 & $3.9 \%$ \\
Other services (except public & & \\
administration) & 4 & $3.9 \%$ \\
Unclassified establishments & 4 & $3.9 \%$ \\
Supervisory Position & & \\
Yes & & \\
No & 16 & $15.5 \%$ \\
& 86 & $83.5 \%$ \\
\hline
\end{tabular}




\section{Procedure}

Data were collected through an online survey. Participants were recruited using the snowball sampling method through various social media networks. The link to the survey, along with a message explaining the purpose of the study, the instructions, and criteria to participate, were posted on several social media websites, including Facebook and LinkedIn. E-mails requesting participation were also sent to the researcher's contacts.

Participants who selected the link were shown a brief description of the study and an informed consent form, after which they were asked to indicate whether they consented to taking the survey. Participants then proceeded to fill out the three sections of the survey, which asked them to provide demographic information and answer questions regarding their identification with their ethnic and dominant cultures, their experiences at work and home, and the amount of social support they received from their direct supervisor. After completing the survey, participants were thanked for their participation.

\section{Measures}

Assimilation level. Assimilation level was measured using the Stephenson Multigroup Acculturation Scale (SMAS) (Stephenson, 2000). The scale consists of 17 items designed to measure the degree of immersion in one's ethnic society (ESI) and 15 items to measure the degree of immersion in one's dominant society (DSI), for a total of 32 items. Sample ESI items include "I know how to speak my native language" and "I think in my native language," whereas sample DSI items include "I attend social 
functions with (Anglo) American people" and "I feel at home in the United States." Participants indicated their level of agreement with each statement on a 4-point Likerttype scale ranging from 1 (false) to 4 (true). Items for these measures were averaged to create composite scores. The higher the score, the more the person is immersed in the ethnic society (ESI) and in the dominant society (DSI). Cronbach's alpha was .92 for ESI and .72 for DSI, indicating good reliabilities. To compute each person's assimilation score, each individual ESI score was subtracted from his or her DSI score. The higher the score, the more the participant was assimilated.

Type of work-family conflict. Type of work-family conflict was measured using two different scales developed by Netemeyer, McMurrian, and Boles (1996); the WorkFamily Conflict Scale and the Family-Work Conflict Scale. Each scale consisted of five items to measure work interference with family or family interference with work, respectively. Sample items on the Work-Family Conflict Scale, which measures work interfering with family (WIF) include "The demands of my work interfere with my home and family life" and "Things I want to do at home do not get done because of the demands my job puts on me." Sample items on the Family-Work Conflict Scale, which measures family interfering with work (FIW) include "The demands of my family or spouse/partner interfere with work-related activities," and "Things I want to do at work do not get done because of the demands of my family or spouse/partner." Participants indicated their level of agreement with each statement on a 7-point Likert-type scale ranging from 1 (strongly disagree) to 7 (strongly agree). Items for these measures were averaged to create composite scores. Higher scores indicate that participants experienced 
more work interference with family, or more family interference with work. Cronbach's coefficient alpha was .94 for the Work Family Conflict scale (WIF) and .88 for the Family Work Conflict scale (FIW).

Perceived supervisor support. Perceived supervisor support was measured using the four-item short version of the Family Supportive Supervisor Behavior scale, developed by Hammer, Kossek, Bodner, and Crain (2013). Sample items include "Your supervisor makes you feel comfortable talking to him/her about your conflicts between work and non-work" and "Your supervisor organizes the work in your department or unit to jointly benefit employees and the company." Participants indicated their level of agreement with each statement on a 5-point Likert-type scale ranging from 1 (strongly disagree) to 5 (strongly agree). A composite score was created as the average of responses to the four scale items, with higher scores indicating that participants perceived more supervisor support. Cronbach's alpha was .92.

Demographic information. Participants were asked to answer 13 demographic questions regarding their gender, age, race/ethnicity, marital and parental status, living structure, and number of financially dependent family members. Questions regarding their employment status included the type of industry, managerial status, the number of direct reports if applicable, and the length of time with current employer and supervisor. 


\section{Results}

\section{Descriptive Statistics}

Table 2 presents the means, standard deviations, Cronbach's alphas, and correlations for the measured variables. As can be seen in the table, participants' assimilation levels ranged from -1.18 to $2.35(M=.62, S D=.75)$. Higher scores indicate more assimilation into the dominant culture. Therefore, the participants were somewhat assimilated. Regarding the outcome variables, participants moderately agreed that they experienced WIF $(M=3.80, S D=1.69)$, but somewhat disagreed that they experienced FIW $(M=2.60, S D=1.34)$. Concerning the moderator variable, participants perceived a moderate level of supervisor support $(M=3.42, S D=1.08)$. These results show that the average participant was somewhat assimilated, experienced more WIF than FIW, and perceived a moderate amount of supervisory support.

Table 2

Means, Standard Deviations, Pearson Correlations, and Cronbach Alphas $(n=103)$

\begin{tabular}{lcccccc}
\hline Measure & $M$ & $S D$ & 1 & 2 & 3 & 4 \\
\hline 1. Assimilation Level & .62 & .75 & & & & \\
2. Perceived Supervisor Support & 3.42 & 1.08 & .07 & $(.92)$ & & \\
3. Work Interference with Family & 3.80 & 1.69 & -.01 & $-.20^{*}$ & $(.94)$ & \\
4. Family Interference with Work & 2.60 & 1.34 & -.03 & -.12 & $.61^{* *}$ & $(.88)$ \\
\hline
\end{tabular}

Note. $* p<.05 . * * p<.01$.

Reliability coefficients (alpha) are presented on the diagonal

\section{Pearson Correlations}

There was no significant relationship between assimilation level and WIF $(r=$ $-.01)$ or between assimilation level and FIW $(r=-.03)$. Interestingly, WIF and FIW were highly correlated $(r=.61, \mathrm{p}<.001)$. Concerning the moderator variable of perceived 
supervisor support, there was a significant negative relationship between perceived supervisory support and WIF $(r=-.20, \mathrm{p}<.001)$, indicating that the more participants felt that their supervisor supported them and cared about their well-being, the less they reported that they experienced WIF. Although a relationship between perceived supervisor support and FIW $(r=-.12)$ was negative, it was not statistically significant.

\section{Test of Hypothesis and a Research Question}

The hypothesis and a research question were tested using a Type I error rate of .05 . Hypothesis 1 stated that the more participants were assimilated, the more they would experience WIF and the less they would experience FIW. Pearson correlations were used to test the hypothesis. As previously mentioned, the correlation between assimilation level and WIF was not statistically significant $(r=-.01)$. The correlation between assimilation level and FIW was also not statistically significant $(r=-.03)$. Therefore, Hypothesis 1 was not supported.

Additionally, a research question was posited to examine whether perceived supervisor support would moderate the relationship between assimilation level and each type of work-family conflict. To assess the moderating effects of perceived supervisor support, two hierarchical regression analyses were performed. For each hierarchical regression analysis, assimilation level and perceived supervisory support were entered in step 1, and the cross product of assimilation level and perceived supervisor support was entered in step 2.

The first model tested whether perceived supervisor support would moderate the relationship between assimilation level and WIF. Table 3 summarizes the results of the 
hierarchical regression analysis. The analysis revealed that assimilation level and perceived supervisor support together accounted for $4.2 \%$ of the variance in WIF ( $\mathrm{p}=$ .13). Although assimilation level was not found to be a significant predictor of WIF ( $\beta=$ $.08, t=.35, p=.73$ ), perceived supervisor support was a significant predictor of WIF ( $\beta=$ $-.32, t=-2.03, p=.05)$. Results of the second step showed that the cross product of assimilation level and perceived supervisor support explained additional $.1 \%$ variance in WIF $(p=.79)$ above and beyond the variance explained by both assimilation level and perceived supervisor support. The interaction term was not statistically significant, indicating perceived supervisor support did not moderate the relationship between identification with assimilation level and $\operatorname{WIF}(\beta=.05, t=.27, p=.79)$.

Table 3

Hierarchical Regression Analysis Summary for Variables Predicting Work Interfering With Family

\begin{tabular}{llllll}
\hline Steps and Predictor Variables & $\mathrm{R}^{2}$ & $\mathrm{R}^{2} \mathrm{adj}$ & $\Delta \mathrm{R}^{2}$ & $\mathrm{r}$ & $\beta$ \\
\hline Step 1: & .042 & .022 & & & \\
Assimilation Level & & & & .02 & .08 \\
Perceived Supervisor Support & & & & $-.20^{*}$ & $-.32^{*}$ \\
$\begin{array}{l}\text { Step 2: } \\
\begin{array}{l}\text { Assimilation Level x } \\
\quad \text { Perceived Supervisor Support }\end{array}\end{array}$ & .043 & .012 & .001 & & \\
\hline
\end{tabular}
Note. ${ }^{*} p<.05$

The second hierarchical regression analysis tested whether perceived supervisor support would moderate the relationship between assimilation level and FIW. Table 4 shows the results of the hierarchical regression analysis. The analysis showed that assimilation level and perceived supervisor support together explained $1.4 \%$ of the variance in FIW $(p=.50)$. Neither assimilation level $(\beta=-.03, t=-.16, p=.87)$ nor 
perceived supervisor support $(\beta=-.15, t=-1.15, p=.25)$ were significant predictors of FIW. Results of step 2 showed that the cross product of assimilation level and perceived supervisor support explained an additional 1\% of the variance in FIW above and beyond the variance explained by both assimilation level and perceived supervisor support ( $p=$ .32). The interaction term was not statistically significant, indicating perceived supervisor support did not moderate the relationship between assimilation level and FIW $(\beta=.15, t=1.00, p=.32)$

Table 4 Hierarchical Regression Analysis Summary for Variables Predicting Family Interference With Work

\begin{tabular}{llllll}
\hline Steps and Predictor Variables & $\mathrm{R}^{2}$ & $\mathrm{R}^{2} a d j$ & $\Delta \mathrm{R}^{2}$ & $\mathrm{r}$ & $\beta$ \\
\hline Step 1: & .014 & -.006 & & & \\
Assimilation Level & & & & -.02 & -.03 \\
Perceived Supervisor Support & & & & -.12 & -.15 \\
Step 2: & .025 & -.007 & .010 & & \\
$\quad \begin{array}{l}\text { Assimilation Level x } \\
\quad \text { Perceived Supervisor Support }\end{array}$ & & & & & \\
\hline
\end{tabular}

In sum, Hypothesis 1 was not supported, indicating that assimilation level was not related to either type of work-family conflict among second generation Latinos and Asians. The results also showed that perceived supervisor support did not moderate the relationship between assimilation level and WIF and the relationship between assimilation level and FIW. However, perceived supervisor support was negatively related to WIF in that the more second generation Latinos and Asians believed their supervisor valued their contributions and cared about their well-being, the less WIF they experienced. 


\section{Discussion}

Demographic changes occurring within the U.S. population are rapidly shaping the U.S. labor force. Among the factors that have contributed to such changes in the labor force is a slowdown in immigration waves paired with high fertility rates among two of the fastest growing ethnic groups, Latinos and Asians. Although the majority of the Latino and Asian groups are mostly composed of immigrants, second generation Latinos and Asians are rapidly increasing in numbers. Therefore, the labor force is undergoing a major generational shift as increasing numbers of today's young U.S.-born Latinos and Asian Americans become employees. Because second generation Latinos and Asians will soon surpass the first generation in the workforce and unlike the first generation, they are likely to be exposed to two different cultures simultaneously; their ethnic culture and the dominant culture of the U.S, it is important to study their unique experiences as employees. Their concurrent exposure to two different cultural value systems could play an important role in their experiences in the workplace.

The present study contributes to the developing research about the effect of cultural variables on the work-family interface, through an examination of second generation Latino and Asian individuals. Because of the exposure to two different cultures, this study proposed that assimilation level might be a unique predictor of the type of work-family conflict they experience among second generation Latinos and Asians. Specifically, the present study examined the relationship between assimilation levels and types of work-family conflict, work-interference with family (WIF) and family interference with work (FIW). 
The current study also proposed perceived supervisor support as a potential moderator because previous research has shown that perceived supervisor support buffers negative outcomes of work-related stress. Therefore, this study examined whether perceived supervisor support would moderate the relationship between assimilation level and WIF among second generation Latinos and Asians. Although perceived supervisor support is often associated with the work domain, supervisors can choose to provide flexible work schedules, or provide time away from work to allow employees to fully handle family responsibilities or emergencies, eliminating frequent and continuous interference with family issues while at work. Given that supervisors are often responsible for the level of work-family balance employees maintain, this study explored whether it would also moderate the relationship between assimilation level and FIW.

Hypothesis 1 stated that the more assimilated second generation Latinos and Asians are, the more WIF and the less FIW they would experience. The hypothesis was not supported. The relationships between assimilation levels and WIF and assimilation levels and FIW were not statistically significant. The lack of a significant relationship between assimilation levels and WIF is inconsistent with the previous research findings that imply assimilation, or identification with the individualistic culture of the U.S. leads to more WIF and less FIW. For example, Olson et al. (2013) found that individualism was positively related to WIF among Caucasian and Latino employees, indicating that the more employees in either group adhered to individualistic values, the more they reported WIF but not necessarily FIW. Gelder (2012) also found that those who reported an orientation reflective of individualism did in fact reported higher levels of WIF than FIW. 
One possible explanation for the lack of a significant relationship between assimilation levels and WFC could be that although the participants were somewhat assimilated in to the dominant culture, they might have also identified with their ethnic culture. The relatively low assimilation levels indicate the possibility of identification with both cultures, which is consistent with previously reported findings. As mentioned earlier, according to the Pew Research Center (2013), only 37\% of second generation Latinos and 27\% of Asian Americans identify themselves as simply "American," choosing instead to identify themselves with their ethnic culture, yet they are likely to speak English, have friends and spouses outside their ethnic group, and define themselves as a "typical American." This contradiction could indicate second generation Latinos and Asians retain the values of both cultures.

Perhaps identification with both cultures protects second generation Latinos and Asians from experiencing WFC. According to Szapocznik (1984), bicultural individuals often develop skills to operate in different value contexts as a means for survival and become accustomed to shifting from one to the other. Similarly, according to Allen (1983), an individual can attain a stress-free balance between his or her work and family domains by maintaining the same values and behaviors in the two roles. Thus, identification with both cultures can be beneficial and complementary to the individual when shifting from one domain to the other (Szapocznik, 1984).

Another explanation could be that second generation Latinos and Asians identify themselves with a third culture, outside of the dominant or ethnic culture. According to Benet-Martínez \& Haritatos (2005), "biculturals tend to see themselves as part of a 
hyphenated culture (or even part of a combined, "third" emerging culture), and find it easy to integrate both cultures in their everyday lives" (pp. 1019). Moreover, Hong, et al. (2000), argues that these individuals do not view their two cultures as exclusive or conflicting. Perhaps identification with a third culture might explain the relatively low assimilation levels and why assimilation levels were not related to either type of workfamily conflict.

An additional explanation might be that most of the participants (82\%) did not have children, were single (66\%), and at an age ( $M=29$ years old) where perhaps they were still launching their careers. Regardless of their assimilation level, the participants may not have been faced with the antecedents, or work/family characteristics, that often lead to WFC. For example, heavy workloads and long hours at work may not interfere with any minimal to non-applicable housekeeping or child care responsibilities within the participants of the study. Therefore, the demographics of the current study's population may be a reason why assimilation levels were not found to be related to more WIF and less FIW.

Perhaps if the majority of the second generation Latino and Asian participants were highly assimilated and had reported more familial responsibilities, they would have shared similar values as Anglo-Americans who identify themselves with the individualist dominant culture, and therefore they might have reported more WIF and less FIW. However, in the present sample, the participants seem to have either identified with both cultures or a third culture, and the majority were single and childless, possibly explaining the lack of a relationship between their relatively low assimilation levels and each type of 
WFC. Alternatively, the results of the present study simply indicate that assimilation levels are not a predictor of WFC for the second generation Latinos and Asians. Finally, had a larger sample been used, the results might have been statistically significant. Therefore, another possible reason for the lack of a significant relationship could be the small statistical power associated with a smaller sample size.

Interestingly, results showed that WIF and FIW were highly related such that the more WIF second generation Latinos and Asians experienced, the more FIW they experienced and vice versa. An explanation for this finding could be that because participants were only slightly assimilated, they identified with both cultures to some level. Perhaps an equal motivation to fulfill the demands of work and family creates an interdependent relationship between WIF and FIW, such that in instances where they do experience conflict in one domain, it might result in conflict in the other. However, this interpretation is speculative and more research is needed.

A research question was posited in order to understand whether perceived supervisor support would moderate the relationship between assimilation level and type of WFC experienced by second generation Latinos and Asians. Results of the hierarchical regression analyses showed that perceived supervisor support did not moderate the relationship between assimilation levels and WIF, or the relationship between assimilation levels and FIW. Perceived supervisor support did not moderate these relationships because assimilation levels may not be related to WFC, as was found in the results of the current study. As past research shows that family and work characteristics have been important antecedents of a specific type of WFC, perhaps they 
need to strongly identify with either culture in order to face the respective work or family demands that are tied to a specific type of WFC, at which point perhaps domain specific support might have an effect on the relationship.

Perceived supervisor support was found to be negatively related to WIF in that the more second generation Latinos and Asians believed their supervisor valued their contributions and cared about their well-being, the less WIF they experienced. Given that supervisor support helped reduce WIF but did not have a significant relationship with FIW in this study, supervisor support might only be relevant to the work domain. This interpretation is consistent with Bellavia and Frone's (2005) assertion that the effects of social support are domain-specific. Therefore, domain-specific social support may act as a barrier against domain-specific antecedents of work-family conflict, explaining why perceived social support was related to less WIF, but was not related to FIW.

\section{Theoretical Implications}

The most important implication of the current study is that it highlighted the need for more research to examine the cultural identification of second generation Latinos and Asians and how their cultural identification could possibly shape their experiences of WFC. Unlike previous research in work-family conflict, the current study introduced assimilation level as a unique predictor of the type of WFC that second generation Latinos and Asians might experience. Although the results of the study did not support the hypothesis, the study introduced the fact that a unique predictor may exist as a result of differences between second generation Latinos and Asians and both the first generation (immigrants) and Anglo-Americans. 
The current study also provides further evidence that perceived supervisor support in the work-domain could reduce WIF. Research has focused much of its attention on this topic because of the positive effects it has on organizations and employees. For example, perceived supervisor support contributes to employees' overall perceptions of the amount of organizational support they receive, as well as helping to reduce employee turnover (Eisenberger et al., 2002). The findings of this study help solidify the theory of perceived supervisor support and WIF.

\section{Practical Implications}

The current study also has some practical implications for organizations and companies that employ second generation Latino and Asian employees. Organizations are responsible for creating the work structure and policies that foster work-family balance. Because supervisors create and implement these polices for their employees, they have a strong influence on employee experiences of WIF, as was found in the current study. Furthermore, the study's findings also imply that perceived supervisor support can reduce WIF regardless of the generation status of employees, highlighting perceived supervisor support as an important topic to address with management-level employees. Organizations should focus on establishing strong support systems from the top down, setting the example to front line supervisors who interact with employees on a daily basis. Investing in resources such as an employee assistance program that supervisors can leverage by referring employees, providing supervisors with sensitivity training, or teaching them how to create an effective yet flexible team environment, could help supervisors establish perceived supervisor support with their team. 


\section{Strengths, Limitations and Directions for Future Research}

One strength of this study is that it studied second generation Latinos and Asians, whose experiences as employees have seldom been examined. Researchers studying work-family conflict have solely focused on the experiences of Anglo-Americans, who are only exposed to the individualistic culture of the U.S. It also examined supervisor support as a moderator in the WFC literature, which to the author's knowledge, has never been studied.

Despite its strength, this study also has some limitations like any other research. First, the sample size was small. The lack of significant relationships might have been due to the lack of statistical power associated with the small sample size. Had a larger sample size been used, the significant relationships might have been obtained. Therefore, the future study should use a larger sample size. The current study should have also eliminated the possible confounding variable of poor assimilation levels. If solely focusing on the effects of identification with the dominant culture, perhaps future research should only include highly assimilated second generation Latinos and Asians to prevent the effects of poor assimilation levels interfering with the results. However, future research could also benefit from examining non-assimilated and assimilated individuals and the type of work-family conflict they experience to identify whether those who are not assimilated experience less WIF, and those who are more assimilated experience more WIF. Finally, future studies could also examine the differences between Anglo-Americans and second generation Latinos and Asians to understand if there is a difference in their experience of WFC. 
Moreover, assimilation levels were gathered using the self-report method. The Stephenson Multigroup Acculturation Scale (SMAS) (Stephenson, 2000) was utilized to create an assimilation level of the participants. The SMAS measures the behavioral and attitudinal aspects of acculturation, but perhaps measuring how participants implicitly identify with the dominant culture instead of utilizing a self-report survey might have yielded better results. Research has shown that it is possible and quite common for explicit attitudes and implicit attitudes to contradict each other (Miramontez, 2010). Second generation Latinos and Asians may be unaware of subconscious attitudes and beliefs regarding their cultures, hence analyzing implicit attitudes might better capture their assimilation levels.

Furthermore, self-report measures rely on the honesty of participants and on their understanding or interpretation of particular questions. Therefore, future research could benefit from utilizing a variation of the Implicit Association Test (IAT), which has been used to develop implicit cognition theories. Such theories attempt to understand and capture cognitive processes that individuals may not be consciously aware of (Miramontez, 2010). For example, Miramontez administered flashes of cultural icons as potential stimuli (e.g., pictures of symbols, dress, flags, food, monuments, celebrities, etc.) to Mexican and Korean Americans in his study. Participants categorized the stimuli as quickly as possible based on several criteria, which resulted in a measure of the relative strength of identification with their applicable ethnic culture: Mexican, or Korean and the dominant U.S. culture. The results found that Mexican Americans implicitly identified more strongly with the Mexican culture than with the American culture, but 
Korean Americans implicitly identified more strongly with the American culture than with the Korean culture.

\section{Conclusion}

In sum, this study sought to examine the relationship between second generation Latino and Asians assimilation levels and whether they would experience more WIF and less FIW, as well as the moderating effects of perceived supervisor support on these relationships. Findings from this study revealed that perhaps assimilation level may not be related to work-family conflict, but that perceived supervisor support does reduce WIF among second generation Latinos and Asians. In addition, the positive finding between WIF and FIW implies that WIF and FIW are not on the opposite end of a single continuum. Future research could benefit from further exploring whether this strong correlation is due to specific characteristics of second generation Latinos and Asians.

An important implication of this research is that perceived supervisor support seems to reduce WIF in general, regardless of cultural identification. Therefore, organizations should look to provide the proper resources and training to their front line supervisors so that they may be able to demonstrate to their employees that their wellbeing matters, and thereby establish a strong perception of supervisor support. An understanding of how to create work environments where second generation Latinos and Asians feel valued and accommodated can be beneficial to organizations across different industries, as increasing numbers of these individuals participate in the U.S. labor force. 


\section{References}

Allen R. (1983). Human stress: Its nature and control. Minneapolis, MN: Burgess Publishing Company.

Allen, T. D. (2001). Family-supportive work environments: The role of organizational perceptions. Journal of Vocational Behavior, 58, 414-435. doi:10.1006/jvbe. 2000.1774

Barnett, R. C., \& Hyde, J. S. (2001). Women, men, work, and family: an expansionist theory. American Psychologist, 56, 781-796. doi:10.1037/0003-066X.56.10.781

Behson, S. J. (2002). Coping with family-to-work conflict: The role of informal work accommodations to family. Journal of Occupational Health Psychology, 7, 324341. doi:10.1037/1076-8998.7.4.324

Bellavia, G., \& Frone, M. R. (2005). Work-family conflict. In J.Barling, E. K.Kelloway, \& M. R.Frone (Eds.), Handbook of work stress (pp. 113-147). Thousand Oaks, CA: SAGE Publication. http://dx.doi.org/10.4135/9781412975995

Benet-Martinez, V., \& Haritatos, J. (2005). Bicultural identity integration (BII): Components and psychological antecedents. Journal of Personality, 73, 10151050. http://dx.doi.org/10.1111/j.1467-6494.2005.00337.x

Carlson, D. S., \& Frone, M. R. (2003). Relation of behavioral and psychological involvement to a new four-factor conceptualization of work-family interference. Journal of Business \& Psychology, 17, 515-535.

Carlson, D. S., \& Perrewé, P. L. (1999). The role of social support in the stressor-strain relationship: An examination of work-family conflict. Journal of Management, 25, 513-540.

Clark, S. C. (2000). Work/family border theory: A new theory of work/family balance. Human Relations, 53, 747-770. doi:10.1177/0018726700536001

Clark, S. C. (2001). Work cultures and work/family balance. Journal of Vocational Behavior, 58, 348-365. doi:10.1006/jvbe.2000.1759

Eisenberger, R., Stinglhamber, F., Vandenberghe, C., Sucharski, I. L., \& Rhoades, L. (2002). Perceived supervisor support: Contributions to perceived organizational support and employee retention. Journal of Applied Psychology, 87(3), 565-573. doi:10.1037/0021-9010.87.3.565 
Etzion, D. (1984). Moderating effect of social support on the stress-burnout relationship. Journal of Applied Psychology, 69, 615-622. doi:10.1037/00219010.69.4.615

Fenwick, R., \& Tausig, M. (2001). Scheduling stress: Family and health outcomes of shift work and schedule control. The American Behavioral Scientist, 44, 11791198 .

Fernandez, J. P. (1986). Child care and corporate productivity: Resolving family/work conflicts. Lexington, MA: Lexington Books.

Fox, M. L., \& Dwyer, D. J. (1999). An investigation of the effects of time and involvement in the relationship between stressors and work-family conflict. Journal of Occupational Health Psychology, 4,164-174. doi:10.1037/1076-8998.4.2.164

Frone, M. R. (2000). Work-family conflict and employee psychiatric disorders: The national comorbidity survey. Journal of Applied Psychology, 85, 888-895. doi:10.1037/0021-9010.85.6.888

Frone, M. R., Russell, M., \& Cooper, M. L. (1992). Antecedents and outcomes of workfamily conflict: Testing a model of the work-family interface. Journal of Applied Psychology, 77, 65-78. doi:10.1037/0021-9010.77.1.65

Fry, R., \& Lowell, B. L. (2002). Work or study: Different fortunes of U.S. Latino. Washington, DC: Pew Hispanic Center.

Fu, C. K., \& Shaffer, M. A. (2001). The tug of work and family: Direct and indirect domain-specific determinants of work-family conflict. Personnel Review, 30, 502-522. http://psycnet.apa.org/doi/10.1108/EUM0000000005936

Gelder, K. M. (2012). Understanding the role of cultural values in the experience of work-family conflict among professional Latinas (Doctoral dissertation). Retrieved from ProQuest Dissertations \& Theses. (915759684).

Gibson, M. A., \& Bhachu, P. K. (1991). The dynamics of educational decision making: A comparative study of Sikhs in Britain and the United States. In M. A.Gibson \& J. U.Ogbu (Eds.), Minority status and schooling: A comparative study of immigrant and involuntary minorities (pp. 63-96). New York: Garland

Greenhaus, J. H., \& Beutell, N. J. (1985). Sources of conflict between work and family roles. Academy of Management Review, 10, 76-88. 
Greenhaus, J. H., Collins, K. M., \& Shaw, J. D. (2003). The relation between workfamily balance and quality of life. Journal of Vocational Behavior, 63, 510-531. doi:10.1016/S0001-8791(02)00042-8

Grzywacz, J. G., \& Marks, N. F. (2000). Reconceptualizing the work-family interface: An ecological perspective on the correlates of positive and negative spillover between work and family. Journal of Occupational Health Psychology, 5, 111-126. doi:10.1037/1076-8998.5.1.111

Grzywacz, J. G., Frone, M. R., Brewer, C. S., \& Kovner, C. T. (2006). Quantifying Work-Family Conflict Among Registered Nurses. Research In Nursing \& Health, 29, 414-426. doi:10.1002/nur.20133

Gutek, B. A., Searle, S., \& Klepa, L. (1991). Rational versus gender role explanations for work-family conflict. Journal of Applied Psychology, 76, 560-568. doi:10.1037 /0021-9010.76.4.560

Hammer, L. B., Ernst Kossek, E., Bodner, T., \& Crain, T. (2013). Measurement development and validation of the Family Supportive Supervisor Behavior Short-Form (FSSB-SF). Journal of Occupational Health Psychology, 18, 285-296. doi:10.1037/a0032612

Higgins, C. A., Duxbury, L. E., \& Irving, R. H. (1992). Work-family conflict in the dual-career family. Organizational Behavior \& Human Decision Processes, 51, 51-75. doi:10.1016/0749-5978(92)90004-Q

Hofstede, G. (1983). The cultural relativity of organizational practices and theories. Journal of International Business Studies, 14(2), 75-89.

Hong, Y. Y., Morris, M., Chiu, C. Y., \& Benet-Martínez, V. (2000). Multicultural minds: A dynamic constructivist approach to culture and cognition. American Psychologist, 55, 709-720. doi/10.1037/0003-066X.55.7.709

Jeffrey Hill, E., Yang, C., Hawkins, A. J., \& Ferris, M. (2004). A cross-cultural test of the work-family interface in 48 countries. Journal of Marriage \& Family, 66, 13001316. doi:10.1111/j.0022-2445.2004.00094.x

Judge, T. A., Ilies, R., \& Scott, B. A. (2006). Work-family conflict and emotions: Effects at work and at home. Personnel Psychology, 59, 779-814. doi: 10.1111/j.17446570.2006.00054.x

Karasek, R. A., Triantis, K. P., \& Chaudhry, S. S. (1982). Coworker and supervisor support as moderators of associations between task characteristics and mental strain. Journal of Occupational Behaviour, 3, 181-200. doi:10.1002/job.403 0030205 
Lindorff, M. (2000). Is it better to perceive than receive? Social support, stress and strain for managers. Psychology, Health \& Medicine, 5, 271-286. doi:10.1080/71369 0199

Mauno, S., Kinnunen, U., \& Pyykkö, M. (2005). Does work-family conflict mediate the relationship between work-family culture and self-reported distress? Evidence from five Finnish organizations. Journal of Occupational And Organizational Psychology, 78(, 509-530. doi:10.1348/096317905X37082

McHale, S. M., \& Crouter, A. C. (1999). Family context and gender role socialization in middle childhood: Comparing girls to boys.. Child Development, 70(4), 990.

Miramontez, D. R. Examining implicit acculturation and bicultural identity integration (Doctoral dissertation). Retrieved from Sociological Abstracts. (1018361117; 201220176)

Near, J. P., Rice, R. W., \& Hunt, R. G. (1978). Work and extra-work correlates of life and job satisfaction. Academy of Management Journal, 21, 248-264. doi:10 $.2307 / 255758$

Netemeyer, R. G., Boles, J. S., \& McMurrian, R. (1996). Development and validation of work-family conflict and family-work conflict scales. Journal of Applied Psychology, 81, 400-410. doi:10.1037/0021-9010.81.4.400

Olson, K. J., Huffman, A. H., Leiva, P. I., \& Culbertson, S. S. (2013). Acculturation and individualism as predictors of work-family conflict in a diverse workforce. Human Resource Management, 52, 741-769. doi:10.1002/hrm.21559

Parasuraman, S., \& Simmers, C. (2001). Type of employment, work-family conflict and well-being: A comparative study. Journal of Organizational Behavior, 22, 551-568. doi:10.1002/job.102

Rice, R. W., Near, J. P., \& Hunt, R. G. (1980). The job-satisfaction/life-satisfaction relationship: A review of empirical research. Basic And Applied Social Psychology, 1, 37-64. doi:10.1207/s15324834basp0101_4

Rodriguez, I. V.Work-family conflict and psychological distress in U.S. Latino mothers and fathers: The moderating effects of familismo and gender (Doctoral dissertation). Retrieved from Sociological Abstracts. (743061764; 201048315).

Ross, L., Desiderio, K., Knudstrup, M., \& Frino, M. (2014). Sales teams or salespersons: Performance implications for embracing individualistic and collectivistic cultural values in a global marketplace. Performance Improvement Quarterly, 53-74. doi:10.1002/piq.21157 
Sam, D. L., \& Berry, J. W. (2010). Acculturation when individuals and groups of different cultural backgrounds meet. Perspectives on Psychological Science,5, 472-481. 10.1177/1745691610373075

Schultz, J. B. \& Henderson, C. (1985). Family satisfaction and job performance: Implications for career development. Journal of Career Development (Springer Science \& Business Media B.V.), 12, 33-47.

Second-Generation Americans: A Portrait of the Adult Children of Immigrants. (2013, February 7). Retrieved April 8, 2014, from http://www.pewsocialtrends.org/2013 /02/07/second-generation-americans/

Spector, P. E., Cooper, C. L., Poelmans, S., Allen, T. D., O'Driscoll, M., Sanchez, J. I., \& $\mathrm{Yu}, \mathrm{S}$. (2004). A cross-national comparative study of work-family stressors, working hours, and well-being: China and Latin America versus the Anglo world. Personnel Psychology, 57, 119-142. doi:10.1111/j.1744-6570.2004.tb0 2486.x

Stephenson, M. (2000). Development and validation of the stephenson multigroup acculturation scale (SMAS). Psychological Assessment, 12, 77-88. doi:10.1037 /1040-3590.12.1.77

Suarez-Orozco, C., \& Suarez-Orozco, M. (1995). Transformations: Immigration, family life, and achievement motivation among Latino adolescents. Stanford, CA: Stanford University Press

Suchet, M., \& Barling, J. (1986). Employed mothers: Interrole conflict, spouse support and marital functioning. Journal of Occupational Behaviour, 7, 167-178. doi:10.1002/job.4030070302

Szapocznik, J. (1984). Bicultural effectiveness training: A treatment intervention for enhancing intercultural adjustment in Cuban American families. Hispanic Journal of Behavioral Sciences, 6, 317-344. doi: 10.1177/07399863840064001

Thompson, C. A., Beauvais, L. L., \& Lyness, K. S. (1999). When work-family benefits are not enough: The influence of work-family culture on benefit utilization, organizational attachment, and work-family conflict. Journal of Vocational Behavior, 54, 392-415. doi:10.1006/jvbe.1998.1681

Toossi, M. (2002). Century of change: The US labor force, 1950-2050, A. Monthly Lab.Rev., 125, 15.

U.S. Census Bureau: Statistical Abstract of the United States. (2012). Retrieved from http://www.census.gov/compendia/statab/ 
Vuong, V. (2010). Acculturation status, filial piety and work-family conflict in ChineseAmericans (Doctoral dissertation). Retrieved from ProQuest Dissertations \& Theses. (305248404).

Yang, N., Chen, C. C., Choi, J., \& Zou, Y. (2000). Sources of work-family conflict: A Sino-U.S. comparison of the effects of work and family demands. Academy of Management Journal, 43, 113-123. doi: 10.2307/1556390 
Appendix

Survey Items

Ethnic Immersion Scale (Stephenson, M., 2000)

1. I speak my native language with my friends and acquaintances from my country of origin.

2. I have never learned to speak the language of my native country.

3. I eat traditional foods from my native culture.

4. I feel comfortable speaking my native language.

5. I am informed about current affairs in my native country.

6. I know how to read and write in my native language.

7. I attend social functions with people from my native country.

8. I feel accepted by (Anglo) Americans.

9. I regularly read magazines of my ethnic group.

10. I know how to speak my native language.

11. I am familiar with the history of my native country.

12. I like to listen to music of my ethnic group.

13. I like to speak my native language.

14. I speak my native language with my spouse or partner.

15 . When I pray, I use my native language.

16. I think in my native language.

17. I stay in close contact with family members and relatives in my native country.

Dominant Immersion Scale (Stephenson, M., 2000)

1. I understand English, but I'm not fluent in English.

2. I am informed about current affairs in the United States.

3. I feel totally comfortable with Anglo American people.

4. I have many (Anglo) American acquaintances.

5. I feel at home in the United States.

6. I feel accepted by (Anglo) Americans.

7. I know how to prepare (Anglo) American foods.

8. I regularly read an American newspaper.

9. I feel comfortable speaking English.

10. I speak English at home.

11. I attend social functions with (Anglo) American people.

12. I am familiar with important people in American history.

13. I think in English.

14. I speak English with my spouse or partner.

15. I like to eat American foods. 
Work-Family Conflict Scale (Netemeyer, Boles, \& McMurrian,1996)

1. The demands of work interfere with my home and family life.

2. The amount of time my job takes up makes it difficult to fulfill family responsibilities.

3. Things I want to do at home do not get done because of the demands my job puts on me.

4. My job produces strain that makes it difficult to fulfill family duties.

5. Due to work related duties, I have to make changes to my plans for family activities.

Family-Work Conflict Scale (Netemeyer, Boles, \& McMurrian, 1996)

6. The demands of my family or spouse/partner interfere with work related activities.

7. I have to put off doing things at work because of demands on my time at home.

8. I have to put off doing things at work because of the demands of my family or spouse/partner.

9. My home life interferes with my responsibilities at work such as getting to work on time, accomplishing daily tasks, and working overtime.

10. Family related strain interferes with my ability to perform job related duties.

Perceived Supervisor Support (Hammer, Kossek, Bodner, \& Crain, 2013)

1. Your supervisor makes you feel comfortable talking to him/her about your conflicts between work and non-work.

2. Your supervisor works effectively with employees to creatively solve conflicts between work and non-work.

3. Your supervisor demonstrates effective behaviors in how to juggle work and nonwork issues.

4. Your supervisor organizes the work in your department or unit to jointly benefit employees and the company. 